\title{
Examining media effectiveness across cultures and national borders: $A$ review and multilevel framework
}

International Journal of Cross Cultural Management II(I) 83-103

(C) The Author(s) 201I Reprints and permissions:

sagepub.co.uk/journalsPermissions.nav DOI: 10.1 I 77//4705958I0389790 ccm.sagepub.com

\section{Karen Moustafa Leonard', James R. Van Scotter², Fatma Pakdil ${ }^{3}$, Nadine Jbeily Chamseddine ${ }^{4}$, Ezel Esatoglu ${ }^{5}$, Murat Gumus ${ }^{6}$, Mustafa Koyuncu ${ }^{7}$, Ling Ling $\mathrm{Wu}^{8}$, Audra I. Mockaitis', Laura Salciuviene $^{10}$, M. Kemal Oktem ${ }^{11}$, Gene Surkiene ${ }^{12}$, and Fu-Sheng Tsai ${ }^{13}$}

\begin{abstract}
We explore the ways that perceptions of media effectiveness are affected by the societal culture, organizational culture, occupational (professional) culture, individual characteristics, and technology acceptance. This is an important subject to explore, as communication is essential to organizational functioning. The continuous drive for communication to individuals in different national and organizational situations around the world, due in part to globalization, leads us to ask: which medium is perceived as the most effective for each of the tasks a manager may be called upon to perform, particularly in different cultures? In other words, is the receiver getting the message that we intend, when the receiver is not in the same situation (societal, organizational, professional, etc.) as the sender? There are contexts of shared values, rules, and experiences that affect communication; words do not have the same meaning and value across languages and cultures (Macnamara, 2004). This means that the message sent from one context may not be the message received in another. If we are not communicating the messages we intend, then our method of communicating may be efficient, but it is certainly not effective. However, there is little research on the effectiveness of media
\end{abstract}

\footnotetext{
I Indiana University-Purdue University Fort Wayne, USA

2 Louisiana State University, Baton Rouge

${ }^{3}$ Baskent University, Ankara, Turkey

${ }^{4}$ Atlanta, GA, United States

${ }^{5}$ Ankara University, Turkey

${ }^{6}$ Canakkale Onsekiz Mart University, Turkey

${ }^{7}$ Nevsehir University, Turkey
}

8 National Taiwan University, Taiwan

Corresponding author:

Karen Moustafa Leonard, Indiana University-Purdue University Fort Wayne, IN, USA

Email: moustafk@ipfw.edu 
types. We develop a framework highlighting the intersection of variables salient to effectiveness: societal, organizational, and occupational culture, individual characteristics, and technology the sender? In the conclusion, we suggest future work that might be appropriate, given the increasing interest in global communication.

\section{Keywords}

communication, communication problems, cultural dimensions, culture, media effectiveness

\section{Introduction}

In this article we explore the ways that perceptions of media effectiveness are affected by the societal culture, organizational culture, occupational (professional) culture, individual characteristics, and technology acceptance. This is an important subject to explore, as communication is essential to organizational functioning. The continuous drive for communication to individuals in different national and organizational situations around the world, due in part to globalization, leads us to ask: which medium is perceived as the most effective for each of the tasks a manager may be called upon to perform, particularly in different cultures? In other words, is the receiver getting the message that we intend, when the receiver is not in the same situation (societal, organizational, professional, etc.) as the sender? It is not uncommon for American or European managers to deal with subsidiaries or suppliers in India or China or Mexico, contexts which are very different from each other.

We believe these questions are critical because there is an increasing drive for worldwide interconnections, often through such computer-mediated communication choices as email and instant messaging. Research indicates that both communication medium and cultural imperatives influence perceptions of communication effectiveness and media choice (Donabedian et al., 1998). There is evidence that task demands influence the selection of media, and that selection of media appropriate to the task is perceived to be more effective (Daft et al., 1987). However, rarely is there a test of whether the media matches the message (that is, media effectiveness) in those studies investigating media richness theory.

There are contexts of shared values, rules, and experiences that affect communications; words do not have the same meaning and value across languages and cultures (Macnamara, 2004). This means that the message sent from one context may not be the message received in another. If we are not communicating the messages we intend, then our method of communicating may be efficient, but it is certainly not effective. However, there is little research on the effectiveness of media types.

We recognize that the within-culture variation between individuals is sometimes more striking than the variation between cultures (Phinney, 1990; Trompenaars, 1994), and it is difficult to deal appropriately with cultural differences without being seen as engaging in stereotyping (Lovitt, 1999). Yuan (1997) stated that communication theories should more appropriately deal with how people communicate, because cultures do not communicate. However, in order to understand our world and to operate within it, some simplification is necessary.

We believe that perceptions of effectiveness are affected by a particular group of interacting variables. Understanding their interrelationships will help increase a manager's performance, and thus, an organization's performance. We begin with the idea of communication and media effectiveness, followed by a brief discussion of culture and the cultural dimensions that we believe are most salient. We then discuss organizational culture, occupational (professional) culture, 
individual characteristics, and technology acceptance, which we believe also contribute to the perceptions of media effectiveness at different levels. This leads to a framework highlighting the intersection of these variables. In the conclusion, we suggest future work that might be appropriate, given the increasing interest in global communication.

Our contribution to the discussion of media effectiveness is not that we are necessarily discussing new concepts, but that our way of envisioning the effects of different variables on media effectiveness and their interrelationships is a move toward a multilevel model, as suggested by many scholars (cf. Bhagat et al., 2003a; Chao and Moon, 2005).

\section{Perceptions of media effectiveness}

Communication is the essence of an organization (Hargie et al., 2002; Katz and Kahn, 1978; Weick, 1987) and a crucial part of the manager's job (Mintzberg, 1973). Organizations are complex systems, dealing in detail with data, information, and knowledge (Galbraith, 1977; Tushman and Nadler, 1978a, 1978b). The choice of media for effective communication is an important issue, particularly where the efficient transfer of data, information, or knowledge is critical. More effective communication, that is, relevant, accurate, timely, and reliable communication (Zmud, 1978), has been shown to result in higher organizational performance overall (Snyder and Morris, 1984). But media effectiveness or quality is a perception, not a fact.

Research has shown that much of the failure or success of joint ventures is linked to communication effectiveness (Czinkota et al., 1998; Kanter and Yatsuko, 1994; Moore and Spekman, 1994). Companies who can mesh relationship maintenance with task accomplishments have a significant competitive advantage, as both are important outcomes of communication (Griffith and Harvey, 2001; Mohr and Nevin, 1990). As the global knowledge economy develops (cf. Drucker, 1993), more and more organizations are becoming aware of the competitive advantage of appropriate and effective communication. Increasing globalization requires both managers and researchers to understand the complex consequences of different communication methods on the receiver's understanding and response, quite apart from the actual message being sent.

Choices of media - methods to communicate a message - may convey many different cues, including importance, urgency, and complexity. Media for transmission of messages can include such forms as face-to-face interactions, written letters or memos, telephone calls, voicemail, email, instance messages, and videoconferences. For example, in certain societies, organizations, or professions, messages in written form may take priority over phone or face-to-face messages, as the organization has institutionalized the importance or criticality of the written form over other forms. In other circumstances, email may be the medium of choice.

There are many different theories that have been proposed to describe the operation of media choices, divided into two main types: media characteristic and social influence theories (Carlson and Davis, 1998). Because of the many excellent reviews on the various theories themselves (cf. Carlson and Zmud, 1999; Fulk and Boyd, 1991; Kock, 2004; Te'eni, 2001; Trevino et al., 2000), we will only discuss the types in general terms.

Media characteristic theories explain media choice as a match of media to the task. However, research has produced inconsistent empirical results (Carlson and Davis, 1998; Carlson and Zmud, 1999; Lee, 1994), which resulted in the channel expansion theory (Carlson and Zmud, 1999), proposing that several factors were involved in media choice. These factors include receiver characteristics, topic of the message, and individual experiences with available media. In the media characteristic theories, an important consideration in media choice is the context in which the 
message is being sent: urgency of the message (Steinfeld and Fulk, 1986; Trevino et al., 1987); level of job pressure, familiarity with technology, and amount of routine in the task (Carlson, and Zmud, 1999; Fulk, 1993); importance and urgency of the decision (Jones et al., 1989); number, importance, and value of decisions, and time constraints (Saunders and Jones, 1990); accessibility of the media (Culnan, 1984, 1985); group size (Miranda and Saunders, 2003); and physical proximity of communicating members (Steinfeld and Fulk, 1986). The theories suggest that understanding of the context of the message is socially constructed (cf. Fulk, 1993; Fulk et al., 1987; Miranda and Saunders, 2003; Webster and Trevino, 1995).

The social influence theories deal primarily with the social interaction of the sender and receiver (Eisenberg and Contractor, 1990; Fulk et al., 1987; Steinfeld and Fulk, 1986). In these theories, media use is seen to give cues that are then processed by the sender and receiver, so media choice is dependent upon how the two interact (Walther, 1992, 1995). Often, how well a medium conveys actual physical presence is considered to be an important consideration in media choice (Short et al. 1976). Physical presence depends on cues beyond simple words (Argyle, 1969; Birdwhistle, 1970). Media effectiveness in this case would be found where social presence cues are present when needed. Research has found that computer-mediated communication, other than those with video, cannot provide such cues (Hiltz and Turoff, 178; Rice, 1984; Rice and Case, 1983). It is intriguing that some researchers found that email has reduced social presence cues (cf. Sproull and Kiesler, 1986) and others found increased cues (Rice and Love, 1987).

Each theory explains some facet of attitudes and behaviors in media choice, and they are likely complementary rather than competing (Trevino et al., 2000), or useful in different communication situations. For example, Zhu et al. (2006) found that social capital theory was more useful for building relationships than in marketing across four target cultures - New Zealand, India, China, and South Africa. Morrow (1981) suggested that a better specified model would take into account media use, media richness, social presence, task requirement, and performance. We agree that a more comprehensive approach would be useful (Trevino et al., 2000). Task goals include managing information, influence, and collaboration (Shelby, 1988), while social goals involve managing credibility, acceptance, and inclusion (Applbaum and Anatol, 1974). A combination of options, strategy, and skill allow managers to communicate successfully (Shelby, 1988).

In general, disruptions in the efficiency of communication occur when there is a lack of cues, such as head nods, eye contact, tone, and inflection (Argyle et al., 1968; Kendon, 1967; Rutter and Stephenson, 1975). Restricting cues results in lessened social presence (Kendon, 1967; LaPlante, 1971) and increased anonymity (Kiesler et al., 1985). Lessened social presence can be a normal part of some interactions. Anonymity may create situations such as flaming, when a sender says things that they might not ordinarily say face to face. However, little work has been done to determine whether similar disruption of efficiency is found in cultures other than those in the West. One common theme is whether a particular medium is able to convey particular types of cues and symbols - those that carry many cues and symbols are generally termed 'rich', while those that carry few cues or symbols are considered less rich (sometimes 'lean'). We will use these terms throughout the paper.

In the next section, we begin to discuss media effectiveness in relation to the first variable: societal culture.

\section{Societal culture}

The dynamic nature of culture and its effect on communication is a crucial point in our discussion. Kroeber and Kluckhohn (1952: 181) described culture as a 'pattern, explicit and implicit of and for 
behavior ... [that can] be considered as products of action ... [and] as conditioning elements of future action'. The values, beliefs, norms, and attitudes of a culture heavily influence individuals living in the culture in the ways they manage and communicate (Hofstede, 1993, 2001). Individuals' interpretations of a particular situation and the choice of behavior are not the same in all cultures, and this can prevent cooperation and understanding (Vallaster, 2005). Berger and Luckmann (1967) and van Maanen and Laurent (1993), among others, argued that the overall society's values and norms are reflected in the attitudes and beliefs of managers (Lodge and Vogel, 1987) and in the ways that they perform their roles (Jackofsky and Slocum, 1988).

One of the primary functions of culture is to define norms for interpersonal communication, as discussed by Samovar et al. (1981: 24):

Culture and communication are inseparable because culture not only dictates who talks with whom, about what, and how the communication proceeds, it also helps to determine how people encode messages, the meanings they have for messages, and the conditions and circumstances under which various messages may or may not be sent, notices, or interpreted. In fact, our entire repertory of communicative behaviors is dependent largely on the culture in which we have been raised. Culture, consequently, is the foundation of communication. And, when cultures vary, communication practices also vary.

In other words, without communication of some kind, there can be no cultural norms or prescriptions. This suggests that culture has a great deal more influence on messages about social units, people, behavior, relationships, and similar topics (symbolic communication) than on less culturally relevant messages (such as messages with data). One of the major parts of a managerial job is communication.

The implicit nature of cultural effects on overall communication across borders and cultures is often overlooked (Weisinger and Trauth, 2003), despite some notable exceptions in the area of email and internet use (e.g. Huang et al., 2003; Ross, 2001). It is clear that culture affects information technology implementation (cf. Kedia and Bhagat, 1988; Veiga et al., 2001), so it is likely that cultural differences affect preferences for communication and the acceptability of various communication approaches. For example, face-to-face communication is preferred in many cultures, but not always for the same reason or in the same circumstances. As illustration, Vallaster (2005) found that Westerners often dominated meeting discussions where Chinese colleagues were present but silent; the true discussions with Chinese colleagues occurred on a one-to-one basis after the meeting, which irritated western supervisors. Also, as we have discussed, restricting cues results in lessened social presence (Kendon, 1967; LaPlante, 1971) and increased anonymity (Kiesler et al., 1985). Lessened social presence and anonymity can be a normal part of some interactions in the West, but social presence in media may be necessary in other societies for media to be perceived as efficient.

Various investigations over different time spans have created many dimensions of culture to consider, including particularism versus universalism (Trompenaars, 1994), mastery versus harmony (Schwartz, 1994), time orientation (Hall, 1959; Hofstede, 2001; Trompenaars, 1994), power distance and uncertainty avoidance (Hofstede, 2001), and individualism versus collectivism (cf. Hofstede, 2001; Triandis, 2002; Trompenaars, 1994). The most commonly used dimension in management sciences research is individualism versus collectivism, because of its centrality to other dimensions (Singelis et al., 1995), although each dimension has its adherents.

Hofstede's work has been considered useful because it is clear and easy to understand (Erez and Earley, 1993). Hofstede's instrument to determine cultural variation is also clear and practical. 
Therefore, we focus on the effects of three of Hofstede's cultural dimensions. First, we examine individualism versus collectivism, because we believe it is central to the other dimensions of Hofstede and those suggested by various cross-cultural scholars. However, we examine power distance and uncertainty avoidance as well because, as we discussed, examining multiple dimensions in a multilevel model will allow us to look at the perceptions of media effectiveness and resulting media choice in a more inclusive fashion. It is not possible to discuss all of the cultural dimensions identified by all of the research; we have chosen these three, which we believe are the most salient to the larger issue of organizational communication processes. Extremes of behavior, as defined in the concept of individualism or collectivism, are infrequent; 'people are always gray - never black or white' (Singelis et al., 1995: 243). Individualism, at the extreme of the continuum, can be considered to be egocentric, and extreme collectivism can be dictatorship. Each of the variations we examine has an effect on communication; in this paper, we have focused on individualism, power distance, and uncertainty avoidance, and they are discussed in relation to perceptions of media efficiency.

Our concern in examining culture and communication is to determine whether three of the many variations of culture help explain the differences in the perceived effectiveness of communication. If we can find cultural variations that best explain the reasons for differences, we can anticipate how best to communicate across societal cultural divides.

\section{Individualism/Collectivism}

Gudykunst (1997) and Gudykunst and Matsumoto (1996) argued that the cultural dimension of individualism explains major differences and similarities in the way individuals communicate. It has frequently been used in research on computer-mediated communication (Rice et al., 1998; Tan et al., 1998).

Research shows that individualists are more direct in their communication and place less emphasis on the thoughts, feelings, and actions of others (Singelis and Brown, 1995). Te'eni (2001) explained some of the difference in communication as resulting from the focus individualists place on finding their differences from each other, making them more likely to seek information about themselves than others (Markus and Kitayama, 1991). Rice et al. (1998) found that people from collectivist cultures prefer synchronous media because they help them understand the other communication partners' reactions to the message and make adjustments necessary for continued group harmony. Erez and Earley (1993) suggested that collectivists emphasize more two-way communication, more personal communication, and more frequent communication, especially to coordinate activities and help clarify decision processes. Collectivists are more likely to use communication that deals with relational issues than are individualists (Ting-Toomey et al., 1991) and are more likely to speak indirectly (Ambady et al., 1996; Holtgraves, 1997), which requires more communication cues to allow the receiver read between the lines (Lee, 1993).

Another distinct difference in communication between individualistic and collectivistic cultures is that individualists emphasize tasks, while collectivists emphasize relationships (Te'eni, 2001). Sanchez-Burks et al. $(2000,2002)$ argued that many individualistic cultures with a Protestant relational ideology consider relational concerns to be inappropriate in the workplace and should be left to extra-curricular activities. This would separate them from their more relational, collectivist counterparts, creating the potential for a great deal of friction at work.

Hall $(1959,1976)$ identified US individualism as low in context, that is, most information is codified and formalized to increase understanding in the multicultural context. In US society in 
particular, creativity and efficiency by individuals is valued and rewarded, leading individuals to restrict their communication with other members of the organization, and increasing the reliance on formal channels. Individualists seek information that is generalized (acontextual) and emphasize the importance of codified information (Triandis, 1990, 1995, 1998). Therefore, lean (less rich) media, that is, media without the need for extra cues or symbols, would be considered more effective.

Communicators from collectivist cultures place more emphasis on high-context communication and attribute meaning to the both context and the receiver's orientation (Hall, 1959, 1976), which can be confusing to those in lower context individualistic cultures. In collectivistic cultures, message content is often embedded in the context of the communication. Thus, the receiver needs contextual cues to interpret the message properly and continually looks for cues in communication (Gudykunst and Ting-Toomey, 1988; Hall, 1976; Markus and Kitayama, 1991; Triandis, 1995, 1998). Therefore, it is likely that collectivists will disregard information and knowledge sent using media that do not have a great many informational and/or social cues (Bhagat et al., 2002), because the communication is ambiguous to them - there are not enough cues for individuals living within the particular society to completely analyze the communication. For example, research on technology acceptance in Japan indicated that usefulness may conflict with the need for social presence cues in determining whether particular communication technologies are supported (Ishida, 1998; Straub, 1994), with definite effects on media choices and availability. Therefore, rich media, that is, media that can convey more cues and symbols, would be perceived as more effective.

Proposition 1: In communicating the same information or knowledge, individuals in societies that are more collectivistic will view richer media as more effective for most functions than will individuals in societies that are more individualistic.

In the next section, we will discuss power distance and its relationship to perceptions of media effectiveness.

\section{Power distance}

Briefly, power is perception; it is the potential to control or influence others, often through control of resources (Dahl, 1957; Emerson, 1962; Pfeffer, 1994). Power distance, as a cultural dimension, is the extent to which a society accepts unequal distributions of power in institutions and organizations (Hofstede, 2001). It is logical to suggest that high power distance cultures are more likely to communicate using different media than in lower power distance cultures. Generally, in high power distance cultures, subordinates expect a clear distinction between themselves and their superiors (Hofstede, 2001; Vallaster, 2005), and the communication preferences likely reflect this. Centralized decision making is the norm in these societies, reducing the acceptability of participative types of information technology, such as email and other types of computer-mediated communication (Abdul-Gadar, 1997; Baba et al., 1996). High interactivity is more effective for control, contextualization, affectivity, and perspective, which are required in cultures with higher power distance (Te'eni, 2001).

On the other hand, low power distance cultures provide an environment that better supports multilevel distribution of data, information, and certain types of knowledge. Members of a low power distance culture tend to be independent workers and, therefore, are likely to have more input into decisions about which media to use (Te'eni, 2001). Therefore, we propose: 
Proposition 2a: In communicating the same information or knowledge, individuals in societies that exhibit higher power distance will be more likely to choose the media considered by their society to be effective for most functions than will individuals in societies that exhibit lower power distance.

Proposition 2b: In communicating information or knowledge, individuals in societies that exhibit lower power distance will be more likely to choose the media considered by their organization or occupation as being more effective than will individuals in societies that exhibit higher power distance.

In the next section, we will discuss the societal dimension of uncertainty avoidance and its relation to media effectiveness.

\section{Uncertainty avoidance}

The amount of uncertainty and ambiguity that an individual can cope with varies among individuals and situations. Uncertainty avoidance as a cultural dimension was espoused by Hofstede (2001) to identify cultures where individuals prefer certainty over uncertainty or ambiguity through such things as structure. For example, Vallaster (2005) found that Chinese subordinates tended to accept situations and decisions rather than question the rationale, but western staff expected that their democratic attitude would allow Chinese employees to choose how they wished to interact within the organizational structure. Vallaster suggested that, when expectations were unclear, particularly regarding such things as roles and responsibilities, all cultural groups were frustrated: Westerners with the lack of input, and Chinese with the lack of direction.

Uncertainty avoidance, as a societal construct, drives members in societies who accept more ambiguity to communicate in ways that are less rich than would be acceptable to organizational members in higher uncertainty avoidance societies. In the same vein, we propose that individual uncertainty avoidance plays a role in choice of media. Participative designs and changes brought about by information technology implementation may be considered risky in high uncertainty avoidance cultures (Abdul-Gadar, 1997; Baba et al., 1996; Hasan and Ditsa, 1999), such as Africa (Entsua-Mensah, 1996) and the Middle East (Danowitz et al., 1995). Therefore, computermediated communication may be less acceptable in societies exhibiting high uncertainty avoidance, reducing their salience as effective media.

Therefore, we suggest that uncertainty versus certainty orientation, as a differentiating societal characteristic, is an important determinant of media choice, specifically:

Proposition 3: In communicating the same information or knowledge, individuals in societies with higher uncertainty avoidance will perceive richer media as being more effective than will individuals in societies with lower uncertainty avoidance.

In the next section, we will discuss organizational and occupational culture influences, which have some similarities to that of societal culture.

\section{Organizational and occupational culture}

Workplace culture consists of organizational and occupational (professional) culture components (Trice, 1993). Some studies focus solely on organizational culture, but we suggest that both are 
influences on workplace perceptions of media effectiveness and, therefore, media choice. Social context is likely to be of help in understanding communication (Fulk et al., 1990), but it is complex and difficult to study (e.g. Kock, 2001).

Each organization has a unique cultural infrastructure, which affects behaviors, activities, decision-making styles, policies, procedures, and communication in the organization (cf. Schein, 2004). Organizational culture has been defined as the

... pattern of basic assumptions that a given group has invented, discovered, or developed in learning to cope with its problems of external adaptation and internal integration and ... [are] taught to new members as the correct way to perceive, think, and feel in relation to those problems. (Schein, 1984: 3)

Occupational culture (sometimes called professional culture) is the 'shared values, beliefs, and norms associated with a particular occupation or type of work' (Heery and Noon, 2001: 242). Some occupations have very definite norms, and these can be static or dynamic. For example, nurses wore white uniforms and caps for over a century, until the move to making professionals more accessible became the more salient norm.

Within organizations and occupations, therefore, there is 'the way we do things around here', where changes may not be acceptable or even, in some cases, permitted. This extends to judgments of acceptable ways to communicate within the organization. Organizational issues include routines (preprogramming) about memos and other messages that are sent within an organization, but sending messages about unusual (non-programmed) circumstances requires that the sender think closely about the medium used, that is, an increase in cognitive effort (Melcher and Beller, 1967). For example, if the manager needed to send a message about the change in healthcare benefits to a subordinate, using the programmed decision for media that is used for general messages may cause the subordinate to either (a) ignore the message as being personally directed or (2) think that the message is not legitimate, as it does not fit the organizational standards. The major difficulties lie in sending non-programmed messages; in some instances they may not be accepted in any medium used, because they are so definitely out of the usual range of messages received.

On a continuum, organizational and occupational cultures can be termed at one extreme as strong and, at the other, as weak. Strong cultures affect behaviors and actions - the greater the agreement among members of the organization or occupation about the shared system of beliefs, values, and symbols of the culture, the stronger that culture is (Schein, 2004). One example of a strong organizational culture is IBM, studied by Hofstede (2001), and an example of a strong occupational culture is the medical profession.

Proposition 4a: Strong organizational and/or occupational cultures will designate the type of communication media that is deemed both appropriate and effective for programmed situations and types of messages.

Proposition 4b: There is likely to be confusion in interpreting and understanding non-programmed messages regardless of the type of media in any organizational or occupational culture.

Proposition 4c: In communicating the same information or knowledge, employees in strong organizational and/or occupational cultures will see leaner (less rich) media as more effective than will employees in weak cultures.

Proposition 4d: In communicating the same information or knowledge, employees in strong organizational and/or occupational cultures will consider formal means of communicating as 
more effective than will employees in weak cultures; therefore, media that enhance formality will be perceived as more effective in strong cultures.

Proposition 4e: In communicating the same information or knowledge, employees in strong organizational and/or occupational cultures will consider structured communication (going through 'channels') as more effective than will employees in weak cultures; therefore, media that enhance structure will be perceived as more effective in strong cultures.

Email may have had the largest effect of any type of media on organizational or occupational structure, in that it flattens hierarchy (Tassabehji and Vakola, 2005). It is usually inexpensive and can be instituted within organizations easily. Email can send one message to an individual or to a group, making it similar to face-to-face communication, but it also has the ability to communicate information that is equivocal and complex (Markus, 1994). However, it has been found to be the least trustworthy of all media, possibly because of the lack of social context (Sproull and Kiesler, 1986; Tassabehji and Vakola, 2005). Organizations that have heavily institutionalized the use of email often find less face-to-face interactions, even when the sender and receiver are in close proximity to each other - they can prefer to send emails than meet face to face (Utley, 1997). However, there are few reports of studies in non-western organizations or occupations.

Proposition 5: Organizations and occupations with flatter structures (lower power distance) than is the norm in the societal culture will perceive email as more effective media (evidenced by their high use) than will those in tall structures.

In the next section, we discuss the effect of individual characteristics on perceptions of media effectiveness.

\section{Individual characteristics}

Often the individual characteristics of the parties and the reason for the communication are important in media choice and, therefore, in perceptions of media effectiveness (Melcher and Beller, 1967; Shelby, 1988). One important characteristic is knowledge level (McCroskey, 1972), which gives indications as to word choice, that is, whether jargon or complex words can be used in the communication (Shelby, 1988).

Proposition 6: In communicating the same information or knowledge, receivers with less knowledge of the topic will consider richer media to be more effective for most functions than will those with more knowledge.

Studies indicate that the use of computer-mediated communication requires an increase in cognitive effort in order to cope with less natural forms of media (Kock, 1998, 2004). In looking at the need for visibility in communication, Boyle et al. (1994) found that face-to-face communication was more efficient in conveying accurate information and in promoting and maintaining interrelationships because all of the cues and channels for communication were available. Studies of cognitive effort increases between email and face-to-face tasks showed that email tasks took longer to complete (Kock, 1998, 1999, 2001; Straus and McGrath, 1994; Suh, 1999). Less natural forms of media were more ambiguous (Carlson and Zmud, 1999; Graetz et al., 1998; Walther, 1995), increasing the risk of incorrect interpretation (Kock, 2002). Multiple studies have found less 
interest in such communication, although it must be noted that these studies were done before the rise in telephone texting and instant messaging as valid forms of media (cf. Bates and Cleese, 2002; Kock, 2002; Olaniran, 1996; Reinig et al., 1995; Sproull and Kiesler, 1986; Zimmer, 2002). Tassabehji and Vakola (2005) and Simon (2006) suggest that we use more familiar media more efficiently; as our confidence level and familiarity with the media rises, so does our view of its efficiency. But findings continue to show an increased satisfaction with natural media over other types.

Proposition 7: Receivers will exhibit more satisfaction with natural media over other types, independent of cultural effects.

We suggest that perceptions of effectiveness or quality of the communication received from a supervisor are related to uncertainty avoidance at the societal level. Individuals cope with uncertainty in two ways: (1) by being comfortable with uncertainty and seeking information directly, i.e. uncertainty oriented; and (2) by being uncomfortable with uncertainty and looking to others for direction, i.e. certainty oriented (Shuper et al., 2004; Sorrentino and Roney, 2000; Sorrentino et al., 2003). We believe that this is likely to have repercussions on the acceptance of communication by the receiver, i.e. its effectiveness. That is, if the receiver is uncertainty oriented, information is accepted although it which might be ambiguous and require some work to identify such things as context or intent. However, if the receiver is certainty oriented, ambiguous messages would be confusing and might be rejected entirely. Therefore, we suggest that certainty versus uncertainty orientation, as a differentiating cultural personality characteristic, is an important determinant of preferred media choice, specifically:

Proposition 8: In communicating the same information or knowledge, certainty oriented individuals will perceive richer media to be more effective for most communication functions than will uncertainty oriented individuals.

In the next section, we discuss technology acceptance and the relation to culture and individual characteristics.

\section{Technology acceptance}

There is a clear overlap between societal, organizational, and occupational culture topics, individual characteristics, and technology acceptance. Many of the issues affecting technology acceptance have been mentioned in the previous sections. It is clear that societal and organization culture affects information technology acceptance and implementation (cf. Kedia and Bhagat, 1988; Veiga et al., 2001), and it is logical that occupational culture does as well. If we look at cultural socialization as being comprised of rules about 'the way we do things around here', then certain types of communication technology will be more acceptable than others in societies, organizations, and professions. At first, the printing press was less acceptable, but it gained popularity as societies, organizations, professions, and individuals realized the gains that could be made from its use. The same process existed with the acceptance of the technologies of typewriter, telephone, video, and computer-mediated communication.

It was initially suggested that the differences in diffusion of technology were the result of economic factors; however, there are marked differences in diffusion rates between nations that are economically similar, including in their cultures (van Ark et al., 2002). The technology acceptance 
model (TAM: Davis, 1989) that has gained such wide acceptance in the management information sciences has been found to be generally limited in its inclusion of these non-economic factors (including culture) and their effect on acceptance (McCoy et al., 2005; Te'eni, 2001).

Kwon and Zmud (1987) have found that, in the West, use of information technologies have failed when there was little support from the top management and/or poor technical design, as well as when the users were untrained or lacked motivation to use the technology. The developing world has the same barriers (Danowitz et al., 1995; Mahmood et al., 1995; Nidumolu and Goodman, 1993). In addition, these less developed countries face lack of capital (Goodman and Press, 1995); unfavorable government regulation (Goodman and Green, 1992); and a lack of infrastructure to support the technology (Odedra et al., 1993). Therefore, technological acceptance is a function of several factors, including societal, organizational, and occupational cultures.

Social and cultural norms help predict whether technology will be used (Karahanna, 1993; Mathieson, 1991; Straub et al., 1997). For example, women in one Kenyan governmental organization were forbidden to use computers, as it allowed them to have more information power than the male managers (Ren, 1998). This relates to the power distance issues discussed in the section on societal culture. Therefore, we suggest that:

Proposition 9: In communicating the same information or knowledge, individuals who less readily accept inequalities (low power distance) will more readily perceive computer-based media as more effective for most functions than will individuals who more readily accept inequalities (high power distance).

The next section will discuss the interactions of the various variables in relation to a framework of media effectiveness.

\section{Framework of media effectiveness}

Individuals use various technologies (media) to draw on and reproduce their social contexts (Orlikowski et al., 1995). Part of the context of work is the societal cultural and its effects on individual perceptions, such as effectiveness, and on behaviors, such as technology acceptance. In this paper, we have chosen to identify the effects of different levels of variables on the perceptions of media effectiveness.

In considering the interactions of communication theory and cultural variations, we have developed a framework, shown in Figure 1. Although we realize that there are other influences, we have focused on communication theory, societal culture, organizational and occupational culture, individual characteristics, and technology acceptance as a starting point for the development of a multilevel (meso-level) theory of communication media effectiveness. Using the framework, we can see that it is likely that individuals make sense of the communications they receive by filtering the communication through these variables.

Our framework is the beginning of the research, not the end. We believe that, in working through the variables described here, we can begin to understand the effects in terms of path analysis, mental schemata, and preferences for media that underlie the framework.

\section{Discussion: Where do we go from here?}

Increasing communication across cultures and national borders makes it essential that we understand the effectiveness of different communicating media, that is, what the use of particular 


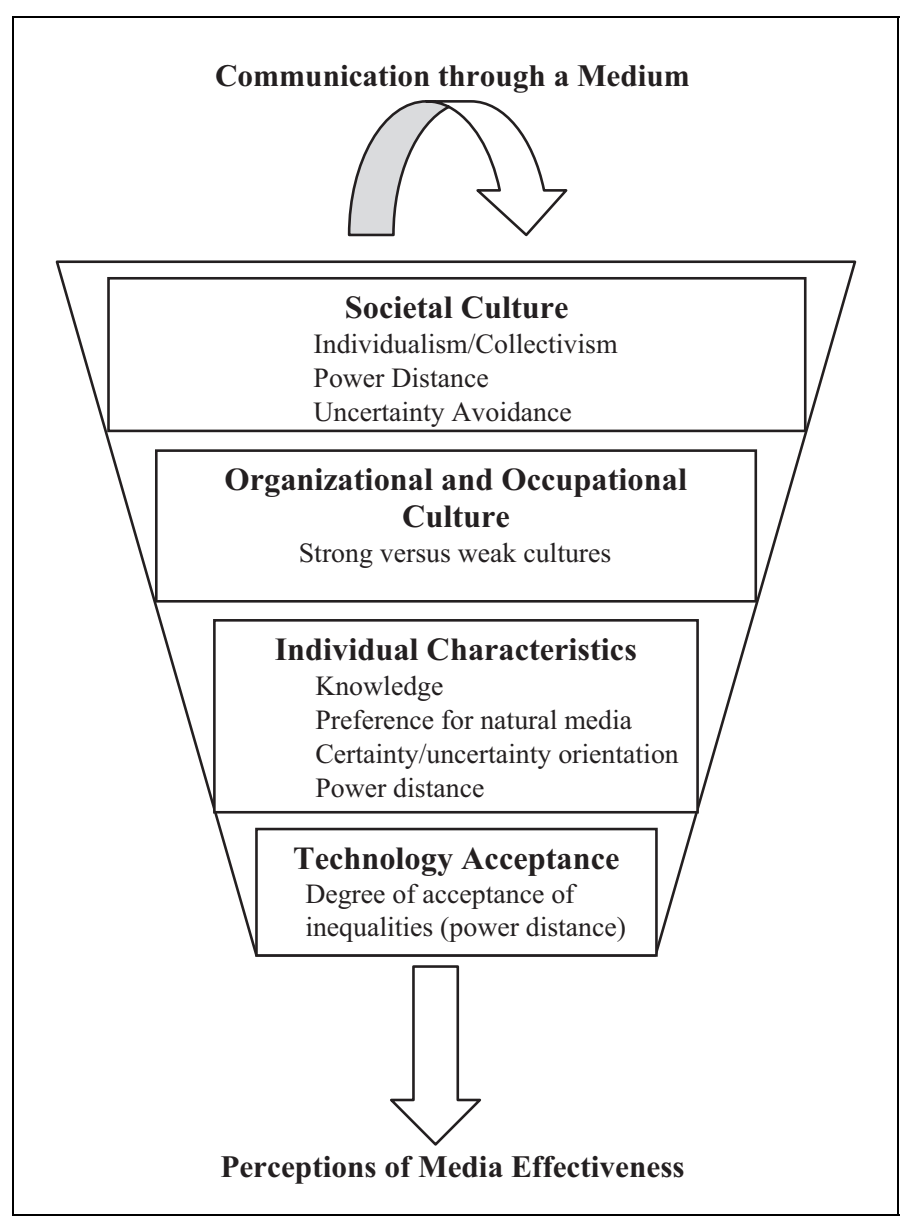

Figure I. A framework for examining media effectiveness across cultures and national borders

media imply to the receiver, aside from the actual message being sent. Understanding the effectiveness of media choices is important in understanding effective organizational communication and can help in designing information and communication technologies (Fulk and Boyd, 1991), organizational success (Mintzberg, 1973), and transfer of knowledge across borders and cultures (Bhagat et al., 2002).

This paper advances conceptual knowledge by presenting new perspectives on the effects of several important variables on perceptions of media effectiveness and, as a result, on the reasons that individuals choose media to use in organizations that span cultures. Our contribution to the discussion of media effectiveness is not that we are necessarily discussing new concepts, but that our way of envisioning their effects on media choice and their interrelationships is a move toward a multilevel model, suggested by many scholars (cf. Bhagat et al., 2003a, 2003b; Chao and Moon, 2005; Earley and Mosakowski, 2002; Miller, 2002; Oysterman et al., 2002; Thomas and Au, 2002; Triandis, 1998).

Despite a great deal of research on media richness, clarity on the issue of media effectiveness remains a challenge. As discussed, there is evidence that task demands influence the selection of 
media, and that selection of media appropriate to the task is perceived to be more effective (Daft et al. 1987). However, we find that rarely is there a test of whether the media matches the message (that is, media effectiveness) in those studies investigating media richness theory. Additionally, we open a further avenue for investigation into theoretical development of communication processes across cultures. Watson-Manheim and Belanger (2007) developed a framework discussing the influence of organizational conditions, such as physical structure, trust, and incentives; situations, such as task characteristic and urgency; and routine on the way that individuals communicate within a firm. We look forward to work incorporating our framework with theirs, perhaps in looking at a wider perspective than media effectiveness.

In this paper, the propositions highlight the complex effects of culture, individual characteristics, and technology acceptance on communication. While our model identifies multiple variables involved in communication processes, we realize it is limited.

Another limitation arises from the difficulty in working in the area of cross-cultural management, which sometimes is considered either ethnocentrism or oversimplification (e.g. Goby, 1999; Weiss, 1998). The within-culture variation between individuals is sometimes more striking than the variation between cultures (Phinney, 1990; Trompenaars, 1994), and it is difficult to deal appropriately with cultural differences without being seen as engaging in stereotyping, as discussed by Lovitt (1999). We agree with Hunsinger (2006) that looking at the world through a lens of universality can result in ethnocentricity, even if the intent is otherwise. Our research attempts to overcome the ethnocentrism by including those from multiple cultures in the design and basic research work of our studies.

Further research possibilities include examining the context of the communication as well as the content, along with perceptions of media effectiveness and the resulting media choices, to highlight some of these points. If given a scenario, media choice could indicate the perceived effectiveness of a type of medium within a particular culture. It might also be possible to consider whether individual preferences are allowed flexibility within societies, organizations, and professions and, if so, in which types.

Intriguing research shows that individuals can be flexible in their reactions to cues about relationships (Sanchez-Burks et al., 2003). In multiple studies, the authors found that Chinese-speaking respondents given an instrument in English responded like Americans did in the other studies; however, those given instruments in Chinese responded more like East Asians. We wonder whether this is true of general communication cues. We hope to incorporate some of this research in our future work.

\section{Acknowledgements}

We would like to thank all our country collaborators (in alphabetical order): Nadine Jbeily Chamseddine, Atlanta, GA, USA; Ezel Esatoglu, Ankara University, Turkey; Murat Gumus, Canakkale Onsekiz Mart University, Turkey; Mustafa Koyuncu, Nevsehir University, Turkey; Ling Ling Wu, National Taiwan University, Taiwan; Audra I. Mockaitis, VictoriaUniversity, New Zealand; Laura Salciuviene, Lancaster University, UK; M. Kemal Oktem, Hacettepe University, Turkey; Gene Surkiene, Vilnius University, Lithuania; Fu-Sheng Tsai, Cheng Shiu University, Taiwan.

\section{References}

Abdul-Gadar H (1997) Information systems strategies in multi-national companies in Arab Gulf countries. International Journal of Information Management 17(1): 3-12. 
Ambady N, Koo J, Lee F, and Rosenthal R (1996) More than words: linguistic and nonlinguistic politeness in two cultures. Journal of Personality and Social Psychology 70: 996-1011.

Applbaum RL and Anatol KWE (1974) Strategies for Persuasive Communication. Columbus, OH: Charles E. Merrill.

Argyle M (1969) Social Interaction. London: Methuen.

Argyle M, Lalljee M, and Cook M (1968). The effects of visibility of interaction in a dyad. Human Relations 21: 3-17.

Baba ML, Falkenburg DR, and Hill DH (1996) Technology management and American culture: implications for business process redesign. Research Technology Management 39(6): 44-54.

Bates B and Cleese J (2001) The Human Face. New York: DK Publishing.

Berger PL and Luckmann T (1967) The Social Construction of Reality. New York: Doubleday.

Bhagat RS, Baliga R, Moustafa K, and Krishnan B (2003) Knowledge in cross-cultural management in the era of globalization: where do we go from here? In: Tjosvold D, Leung K (eds), Cross-Cultural Management: Foundations and Future. London: Ashgate, 155-75.

Bhagat RS, Kedia BL, Harveston PD, and Triandis HC (2002) Cultural variations in the cross-border transfer of organizational knowledge: an integrative framework. Academy of Management Review 27(2): 204-21.

Bhagat RS, Kedia BL, Perez LM, and Moustafa K (2003) The role of subjective culture in organizations: progress and pitfalls twenty years later. In: Punnett BJ and Shenkar O (eds) Handbook of International Management Research. Ann Arbor: University of Michigan Press, 189-209.

Birdwhistle RL (1970) Kinesics and Context. Philadelphia: University of Philadelphia Press.

Boyle EA, Anderson AH, and Newlands A (1994) The effects of visibility on dialogue and performance in a cooperative problem-solving task. Language and Speech 37(1): 1-20.

Carlson JR and Zmud RW (1999) Channel expansion theory and the experiential nature of media richness perceptions. Academy of Management Journal 42(2): 153-70.

Carlson PJ and Davis GB (1998) An investigation of media selection among directors and managers: from 'self' to 'other' orientation. MIS Quarterly 22(3): 335-62.

Chao GT and Moon H (2005) The cultural mosaic: a metatheory for understanding the complexity of culture. Journal of Applied Psychology 90(6): 1128-40.

Culnan MJ (1984) The dimensions of accessibility to online information: Implications for implementing office information systems. ACM Transactions on Office Information Systems 2(2): 141-50.

Culnan MJ (1985) The dimensions of perceived accessibility of information: implications for the delivery of information systems and services. Journal of the American Society for Information Science 36(5): 302-8.

Czinkota M, Ronkainen I, Moffett M, and Moynihan E (1998) Global Business. New York: Dryden.

Daft RL, Lengel RH, and Trevino LK (1987) Message equivocality, media selection, and manager performance: implications for information systems. MIS Quarterly 11: 355-66.

Dahl RA (1957) The concept of power. Behavioral Science 2: 201-18.

Danowitz AK, Nassef Y, and Goodman SE (1995) Cyberspace across the Sahara: computing in North Africa. Communications of the ACM 38(120): 23-8.

Davis FD (1989) Perceived usefulness, perceived ease of use, and user acceptance of information technology. MIS Quarterly 13(3): 319-40.

Donabedian B, McKinnon SM, and Bruns WJ Jr. (1998) Task characteristics, managerial socialization, and media selection. Management Communication Quarterly 11(3): 372-400.

Drucker P (1993) Post-Capitalist Society. New York: HarperCollins.

Earley PC and Mosakowski E (2002) Linking culture and behavior in organizations: suggestions for theory development and research methodology. In: Yammarino FJ, Dansereau F (eds) Research in Multi-Level Issues, vol. 1, The Many Faces of Multi-Level Issues. New York: JAI, 297-319.

Eisenberg EMand Contractor NS (1990). Communication networks and new media in organizations. In: Fulk J, Steinfeld C (eds) Organizations and Communication Technology. Newbery Park, CA: SAGE, $143-72$. 
Emerson RM (1962) Power-dependence relations. American Sociological Review 27: 31-41.

Entsua-Mensah C (1996) Toward effective information management: a view from Ghana. International Journal of Information Management 16(2): 149-56.

Erez M and Earley PC (1993) Culture, Self-Identity, and Work. Oxford: Oxford University Press.

Fulk J (1993) Social construction of communication technology. Academy of Management Journal 36(5): 921-34.

Fulk J and Boyd B (1991) Emerging theories of communication in organizations. Journal of Management 17: 407-46.

Fulk J, Schmitz J, and Steinfield CJ (1990) A social influence model of technology use. In: Fulk J, Steinfield C (eds) Organizations and Communication Technology. Thousand Oaks, CA: SAGE, 117-40.

Fulk J, Steinfeld C, Schmitz J, and Power JG (1987) A social information processing model of media use in organizations. Communication Research 14(5): 529-52.

Galbraith JR (1977) Organization Design. Reading, MA: Addison-Wesley.

Goby VP (1999) All business students need to know the same things! The non-culture-specific nature of communication needs. Journal of Business and Technical Communication 13: 179-89.

Goodman SE and Green JD (1992) Computing in the Middle East. Communications of the ACM 35(8): 21-5.

Goodman SE and Press LI (1995) Computing in Vietnam: Asian tiger in the rough. Communications of the $A C M$ 38(1): 11-16.

Graetz KA, Boyle ES, Kimble CE, Thompson P, and Garloch JL (1998) Information sharing in face-to-face, teleconferencing, and electronic chat groups. Small Group Research 29: 714-43.

Griffith DA and Harvey MG (2001) Executive insights: an intercultural communication model for use in global interorganizational networks. Journal of International Marketing 9(3): 87-103.

Gudykunst WB (1997) Cultural variability in communication. Communication Research 24(4): 327-48.

Gudykunst WB and Matsumoto Y (1996) Cross-cultural variability of communication in personal relationships. In Gudykunst WB, Ting-Toomey S, and Nishida T (eds) Communication in Personal Relationships across Cultures. Newbury Park, CA: SAGE, 19-55.

Gudykunst WB and Ting-Toomey S (1988) Culture and affective communication: universality of emotion expression and recognition. American Behavioral Scientist 31(3): 384-400.

Hall ET (1959) The Silent Language. Garden City NY: Anchor Books/Doubleday.

Hall ET (1976) Beyond Culture. Garden City, NY: Anchor Books.

Hargie O, Tourish D, and Wilson N (2002) Communication audits and the effects of increased automation: a follow-up study. Journal of Business Communication. 39(4): 414-36.

Hasan H and Ditsa G (1999) The impact of culture on the adoption of IT: an interpretive study. Journal of Global Information Management 7(1): 5-15.

Heery E and Noon M (eds) (2001) A Dictionary of Human Resource Management. Oxford: Oxford University Press.

Hiltz SR and Turoff M (1978) The Network Nation. Menlo Park, CA: Addison-Wesley.

Hofstede G (1993) Cultural constraints in management theories. Academy of Management Executive 1: 81-94.

Hofstede G (2001) Culture's Consequences: International Differences in Work Related Values, 2nd edn. Beverly Hills, CA: SAGE.

Holtgraves T (1997) Styles of language use: individual and cultural variability in conversation indirectness. Journal of Personality and Social Psychology 73: 624-37.

Huang L, Lu M, and Wong BK (2003) The impact of power distance on email acceptance: evidence from the PRC. Journal of Computer Information Systems 44(1): 93-101.

Hunsinger RP (2006). Culture and cultural identity in intercultural technical communication. Technical Communication Quarterly 15(1): 31-48.

Ishida M (1998) Information and communications technology and jobs creator or destroyer? In: The World Bank Virtual Symposium on Information and Communications Technology, Jobs, and Work: Challenge for Development, New Delhi, May-July. 
Jackofsky EF and Slocum JW (1988) CEO roles across cultures. In: Hambrick DC (ed.) The Executive Effect: Concepts and Methods for Studying Top Managers. Greenwich CT: JAI Press, 319-34.

Jones J, Saunders CS, and McLeod RJ (1989) Information media and source patterns across management levels: a pilot study. Journal of Management Information Systems 5(3): 71-84.

Kanter R and Yatsuko P (1994) People first. CIO 8(1): 22-4.

Karahanna E (1993) Evaluative criteria and user acceptance of end-user information technology: a study of end user cognitive and affective processes. University of Minesota, PhD dissertation.

Katz D and Kahn RL (1978) The Social Psychology of Organizations. New York: Wiley.

Kedia BL and Bhagat RS (1988) Cultural constraints on transfer of technology across nations: implications for research in international and comparative management. Academy of Management Review 13(4): 559-71.

Kendon A (1967) Some functions of gaze direction in social interaction. Acta Psychologica 26: 1-47.

Kiesler S, Zubrow D, Moses A, and Geller V (1985) Affect in computer-mediated communication: an experiment in synchronous terminal-to-terminal discussion. Human-Computer Interaction 1(1): 77-104.

Kock N (1998) Can communication medium limitations foster better group outcomes? An action research study. Information and Management 34: 295-305.

Kock N (1999) Process Improvement and Organizational Learning: The Role of Collaboration Technologies. Hershey, PA: Idea Group.

Kock N (2001) The ape that used email: understanding e-communication behavior through evolution theory. Communications of the Association for Information Systems 5(3): 1-29.

Kock N (2002) Managing with web-based IT in mind. Communications of the ACM 45(5): 102-6.

Kock N (2004) The psychobiological medium: toward a new theory of computer-communication based on Darwinian evolution. Organization Science 15(3): 327-48.

Kroeber AL and Kluckhohn F (1952) Culture: A Critical Review of Concepts and Definitions. Cambridge MA: Harvard University Press.

Kwon TH and Zmud RW (1987). Unifying the fragmented models of information system implementation. In: Boland RJ, Hirschheim RA (eds) Critical Issues in Information Systems Research. Chichester: Wiley, 227-51.

LaPlante D (1971) Communication, friendliness, trust, and the prisoner's dilemma. University of Windsor, Canada, Master's degree.

Lee AS (1994) Electronic mail as a medium for rich communication: an empirical investigation using hermeneutic interpretation. MIS Quarterly 18(2): 143-57.

Lee F (1993) Being polite and keeping MUM: how bad news is communicated in organizational hierarchies. Journal of Applied Social Psychology 23: 1124-49.

Lodge GC and Vogel EF (eds) (1987) Ideology and National Competitiveness. Boston, MA: Harvard Business School Press.

Lovitt CR (1999) Rethinking the role of culture in international professional communication. In: Lovitt CR, Goswami D (eds) Exploring the Rhetoric of International Professional Communication: An Agenda for Teachers and Researchers. Amityville, NY: Baywood, 1-13.

McCoy S, Galletta DF, and King WR (2005) Integrating national culture into IS research: the need for current individual-level measures. Communications of the Association for Information Systems 15: 211-24.

McCroskey JC (1972) A summary of experimental research on the effects of evidence in persuasive communication. In: The Process of Social Influence. Englewood Cliffs, NJ: Prentice Hall, 318-28.

Macnamara JR (2004) The crucial role of research in multicultural and cross-cultural communication. Journal of Communication Management 8(3): 322-34.

Mahmood MA, Gemoets LA, and Gosler MD (1995) Information technology transfer and diffusion to Mexico: a preliminary analysis. Journal of Global Information Management 3(4): 5-15.

Markus MA (1994). Electronic mail as the medium of managerial choice. Organization Science 5(4): 502-37. 
Markus H and Kitayama S (1991) Culture and self: implications for cognition, emotion, and motivation. Psychological Review 98: 224-53.

Mathieson K (1991) Predicting user intentions: comparing the technology acceptance model with the theory of planned behavior. Information Systems Research 2(3): 173-91.

Melcher AJ and Beller R (1967) Toward a theory of organizational communication: consideration in channel selection. Academy of Management Journal 10(1): 39-52.

Miller JG (2002). Bringing culture to basic psychological theory: beyond individualism and collectivism. comment on Oyserman et al (2002). Psychological Bulletin 128: 89-98.

Mintzberg H (1973) The Nature of Managerial Work. New York: Harper \& Row.

Miranda SM and Saunders CS (2003) The social construction of meaning: an alternative perspective on information sharing. Information Systems Research 14(1): 87-106.

Mohr J and Nevin JR (1990) Communication strategies in marketing channels: a theoretical perspective. Journal of Marketing 54(4): 36-51.

Moore J and Spekman R (1994) Characteristics of partnership success: partnership, attributes, communication behavior, and conflict resolution techniques. Strategic Management Journal 5: 135-52.

Morrow P (1981) Work-related communication, environmental uncertainty, and subunit effectiveness: a second look at the information processing approach to subunit communication. Academy of Management Journal 24(4): 851-8.

Nidumolu SR and Goodman SE (1993) Computing in India: an Asian elephant learns to dance. Communications of the ACM 36(6): 15-22.

Odedra M, Lawrie M, Bennett M, and Goodman SE (1993) Sub-Saharan Africa: a technological desert. Communications of the ACM 36(6): 15-22.

Olaniran BA (1996) A model of group satisfaction in computer-mediated communication and face-to-face meetings. Behaviour and Information Technology 15(1): 24-36.

Orlikowski WJ, Yates JA, Okamura K, and Fujimoto M (1995) Shaping electronic communication: the metastructuring of technology in the context of use. Organization Science 6(4): 423-44.

Oysterman D, Kemmelmeier M, and Coon H (2002) Cultural psychology, a new look: reply to Bond (2002), Fiske (2002), and Miller (2002). Psychological Bulletin 128(1): 110-17.

Pfeffer J (1994) Managing with Power: Politics and Influence in Organizations. Boston, MA: Harvard Business School Press.

Phinney JS (1990) Ethnic identity in adolescents and adults: review of research. Psychological Bulletin 108 (3): 499-514.

Reinig BA, Briggs RO, Shepherd MM, Yen J, and Nunamaker JF Jr. (1995) Affective reward and the adoption of group support systems: productivity is not always enough. Journal of Management Information Systems 12: $171-85$.

Ren L (1998) Information and communications technology and enterprise: the new business environment. In: The World Bank Virtual Symposium on Information and Communications Technology, Jobs, and Work: Challenge for Development, New Delhi, May-July.

Rice RE (1984) Mediated Group Communication; The New Media. Communication, Research, and Technology. Beverly Hills, CA: SAGE, 129-54.

Rice RE and Case D (1983) Electronic messaging systems in the university: a description of use and utility. Journal of Communication 33(1): 131-52.

Rice RE and Love G (1987) Electronic emotion: socio-emotional content in a computer-mediated communication network. Communication Research 14(1): 85-108.

Rice RE, D'Ambra J, and More E (1998) Cross-cultural comparison of organizational media evaluation and choice. Journal of Communication 48(3): 3-26.

Ross DN (2001). Electronic communications: do cultural dimensions matter? American Business Review (June): $75-81$.

Rutter DR and Stephenson GM (1975) The role of visual communication in synchronizing conversation. European Journal of Social Psychology 7: 29-37. 
Samovar LA, Porter RE, and Jain NC (1981) Understanding Intercultural Communication. Belmont, CA: Wadsworth.

Sanchez-Burks J, Lee F, Choi I, Nisbett RE, Zhao S, and Koo J (2003) Conversing across cultures: East-West communication styles in work and nonwork cultures. Journal of Personality and Social Psychology 85(2): $363-72$.

Sanchez-Burks J, Nisbett RE, and Ybarra O (2000) Cultural styles, relational schemes, and prejudice against outgroups. Journal of Personality and Social Psychology 79: 174-89.

Saunders CS and Jones J (1990) Temporal sequences in information acquisition for decision making: a focus on source and medium. Academy of Management Review 15(1): 29-46.

Schein EH (1984) Coming to a new awareness of organizational culture. Sloan Management Review 25(2): $3-16$.

Schein EH (2004) Organizational Culture and Leadership, 3rd edn. San Francisco: Jossey-Bass.

Schwartz SH (1994). Beyond individualism/collectivism: new dimensions of values. In: Kim U, Triandis HC, Kagitcibasi C, Choi SC, and Yoon G (eds) Individualism and Collectivism: Theory, Application, and Methods. Newbury Park, CA: SAGE, 1-65.

Shuper PA, Sorrentino RM, Otsubo Y, Hodson G, and Walker AM (2004) A theory of uncertainty orientation: implications for the study of individual differences within and across cultures. Journal of Cross-Cultural Psychology 35(4): 460-80.

Shelby AN (1988) A macro theory of management communication. Journal of Business Communication 25 (2): $13-27$.

Short J, Williams E, and Christie B (1976) The Social Psychology of Telecommunications. London: Wiley.

Simon AF (2006) Computer-mediated communication: task performance and satisfaction. Journal of Social Psychology 146(3): 349-79.

Singelis TM, Brown WJ (1995) Culture, self, and collectivist communication: linking culture to individual behavior. Human Communication Research 21: 354-89.

Singelis TM, Triandis HC, Bhawuk DPS, and Gelfand M (1995) Horizontal and vertical dimensions of individualism and collectivism: a theoretical and measurement refinement. Cross-Cultural Research 29: 240-75.

Snyder RAand Morris JH (1984) Organizational communication and performance. Journal of Applied Psychology 69: 461-5.

Sorrentino RM and Roney CJR (2000) Uncertainty orientation, achievement-related motivation, and task diagnosticity as determinants of task performance. Social Cognition 4: 420-36.

Sorrentino RM, Smithson M, Hodson G, Roney CJR, and Marie Walker A (2003) The theory of uncertainty orientation: a mathematical reformulation. Journal of Mathematical Psychology 47: 132-49.

Sproull L and Kiesler S (1986) Reducing social context cues: electronic mail in organizational communication. Management Science 32(11): 1492-1512.

Steinfeld C and Fulk J (1986) Task demands and managers' use of communication media: an information processing view. Paper presented at the annual meeting of the Academy of Management, Chicago.

Straub DW (1994) The effect of culture on information technology diffusion: email and fax in Japan and the US. Information Systems Research 5(1): 23-47.

Straub DW, Kiel M, and Brennan W (1997) Testing the technology acceptance model across cultures: a three country study. Information and Management 33: 1-11.

Strauss SG and McGrath JE (1979) Does the medium matter? The interaction of task type and technology on group performance and member reactions. Journal of Applied Psychology 79(1): 87-97.

Suh KS (1999) Impact of communication medium on task performance and satisfaction: an examination of media-richness theory. Information and Management 35: 295-312.

Tan BCY, Wei KK, Watson RT, Clapper DL, and McLean ER (1998) Computer-mediated communication and majority influence: assessing the impact in an individualistic and in a collectivistic culture. Management Science 44(9): 1263-78. 
Tassabehji R and Vakola M (2005) Business email: the killer impact. Communication of the ACM 48(11): 64-70. Te'eni D (2001). Review: a cognitive-affective model of organizational communication for designing IT. MIS Quarterly 25(2): 251-312.

Thomas DC and Au K (2002) The effect of cultural differences on behavioral responses to low job satisfaction. Journal of International Business Studies 32(2): 309-26.

Ting-Toomey S, Gao G, Trubisky P, Yang Z, Kim HS, Lin S-L, and Nishida T (1991) Culture, face maintenance, and styles of handling interpersonal conflict: a study in five cultures. International Journal of Conflict Resolution 2: 275-96.

Trevino LK, Lengel RH, and Daft RL (1987) Media symbolism, media richness, and media choice in organizations. Communication Research 14(5): 553-74.

Trevino LK, Webster J, and Stein EW (2000) Making connections: complementary influences on communication media choices, attitudes, and use. Organization Science 11(2): 163-82.

Triandis HC (1990) Cross-cultural studies of individualism and collectivism. In: Berman JJ (ed.) Nebraska Symposium on Motivation, vol. 37. Lincoln: University of Nebraska Press, 41-133.

Triandis HC (1995) Individualism and Collectivism. Boulder, CO: Westview.

Triandis HC (1998) Vertical and horizontal individualism and collectivism: theory and research implications for international comparative management. Advances in International Comparative Management 12: 7-35.

Triandis HC (2002) Generic individualism and collectivism. In Gannon MJ, Newman KL (eds) The Blackwell Handbook of Cross-Cultural Management. Oxford: Blackwell Business, 16-45.

Trice HM (1993) Occupational Subcultures in the Workplace. Ithaca, NY: ILR Press.

Trompenaars F (1994) Riding the Waves of Culture: Understanding Cultural Diversity in Business. Chicago: Irwin.

Tushman ML and Nadler DA (1978a) An information processing approach to organizational design. Academy of Management Review 3: 613-24.

Tushman ML and Nadler DA (1978b) Information processing as an integrating concept in organization design. Academy of Management Review 3: 613-24.

Utley A (1997) Abusive emails ignite work fury. Times Higher Education Supplement (30 May): 1.

Vallaster C (2005) Cultural diversity and its impact on social interactive processes. International Journal of Cross Cultural Management 5(2): 139.

van Ark B, Inklaar R, and McGuckin RH (2002) Changing Gear. Productivity, Information and Communication Technology, and Service: Europe and the United States. Research Memorandum GD-60. Groningen, Netherlands: University of Groningen and Groningen Growth and Development Centre.

van Maanen J, Laurent A (1993) The how of culture: some notes on globalization and the multinational corporation. In Ghoshal S, Westney DE (eds) Organization Theory and the Multinational Corporation. New York: St Martin's Press, 273-312.

Veiga JF, Floyd S, and Dechant K (2001) Towards modeling the effects of national culture on IT implementation and acceptance. Journal of Information Technology 16: 145-58.

Walther JB (1992) Interpersonal effects in computer-mediated interaction: a relational perspective. Сотmunication Research 19(1): 52-90.

Walther JB (1995) Relational aspects of computer-mediated communication: experimental observations over time. Organization Science 6(2): 186-203.

Watson-Manheim MB and Belanger F (2007). Communication media repertoires: dealing with the multiplicity of media choices. MIS Quarterly 31(2): 267-93.

Webster J and Trevino LK (1995) Rational and social theories as complementary explanations of communication media choice: two policy-capturing studies. Academy of Management Journal 38(6): 1544-72.

Weisinger JY and Trauth EM (2003) The importance of situating culture in cross-cultural IT management. IEEE Transactions on Engineering Management 50(1): 26.

Weick KE (1987) Theorizing about organizational communication. In: Jablin FM, Putnam LL, Roberts KH, and Porter LW (eds) Handbook of Organization Communication. Newbury Park, CA: SAGE, 97-122. 
Weiss E (1998) Technical communication across cultures: five philosophical questions. Journal of Business and Technical Communications 12: 253-69.

Yuan R (1997) Yin/yang principle and the relevance of externalism and paralogical rhetoric to intercultural communication. Journal of Business and Technical Communication 11(2): 297-320.

Zhu Y, Nel P, and Bhat R (2006) A cross cultural study of communication strategies for building business relationships. International Journal of Cross Cultural Management 6(3): 319-41.

Zimmer C (2002) Evolution: The Triumph of an Idea. New York: HarperCollins.

Zmud R (1978). An empirical investigation of the dimensionality of the concept of information. Decision Sciences 9: 187-95. 